\title{
Not All Doom and Gloom: How Energy-Intensive and Temporally Flexible Data Center Applications May Actually Promote Renewable Energy Sources
}

\author{
Gilbert Fridgen · Marc-Fabian Körner - Steffen Walters • Martin Weibelzahl
}

Received: 1 July 2020/ Accepted: 5 January 2021 / Published online: 9 March 2021

(C) The Author(s) 2021

\begin{abstract}
To achieve a sustainable energy system, a further increase in electricity generation from renewable energy sources (RES) is imperative. However, the development and implementation of RES entail various challenges, e.g., dealing with grid stability issues due to RES' intermittency. Correspondingly, increasingly volatile and even negative electricity prices question the economic viability of RES-plants. To address these challenges, this paper analyzes how the integration of an RES-plant and a computationally intensive, energy-consuming data center (DC) can promote investments in RES-plants. An optimization model is developed that calculates the net present value (NPV) of an integrated energy system (IES) comprising an RES-plant and a DC, where the DC may directly consume electricity from the RES-plant. To gain applicable knowledge, this paper evaluates the developed model by
\end{abstract}

Accepted after one revision by the editors of the special issue.

Supplementary Information The online version contains supplementary material available at https://doi.org/10.1007/s12599021-00686-z.

G. Fridgen

SnT - Interdisciplinary Center for Security, Reliability and

Trust, University of Luxembourg, Luxembourg, Luxembourg

G. Fridgen · M.-F. Körner $(\bowtie) \cdot$ M. Weibelzahl

Project Group Business and Information Systems Engineering of the Fraunhofer FIT, Bayreuth, Germany

e-mail: marc.koerner@fim-rc.de

M.-F. Körner · M. Weibelzahl

FIM Research Center, University of Bayreuth, Bayreuth, Germany

S. Walters

FIM Research Center, University of Augsburg, Augsburg, Germany means of two use-cases with real-world data, namely AWS computing instances for training Machine Learning algorithms and Bitcoin mining as relevant DC applications. The results illustrate that for both cases the NPV of the IES compared to a stand-alone RES-plant increases, which may lead to a promotion of RES-plants. The evaluation also finds that the IES may be able to provide significant energy flexibility that can be used to stabilize the electricity grid. Finally, the IES may also help to reduce the carbon-footprint of new energy-intensive DC applications by directly consuming electricity from RES-plants.

Keywords Energy informatics · Integrated energy system · Data center · Renewable energy sources · Energy flexibility - Machine learning · Cryptocurrency mining · Bitcoin · Edge computing

\section{Introduction}

In line with the Paris Agreement and the United Nations sustainability goals, i.e., the development and implementation of a sustainable energy system including a phase-out of fossil power plants, the share of renewable energy sources (RES) in the global energy mix has already risen significantly in the past years and continues to grow steadily (United Nations 2015). Despite decreasing carbon dioxide emissions, the increasing share of RES also poses several challenges: On the grid level, the inherent intermittency of RES leads to challenges for grid stability and requires cost-intensive congestion management (Rausch et al. 2019). In Germany alone, these circumstances yielded costs of $€ 1.5$ bn in 2018 for redispatch interventions (Bundesnetzagentur 2019). Ultimately, as both electricity grids and electricity demand have not yet been adjusted to 
the new generation structure of high shares of RES, the intermittent electricity supply of RES can ultimately not be optimally used within the system (Linnemann et al. 2011; Nieße et al. 2012). This demonstrates an increased need for flexibility, referring to the ability to balance electricity demand and supply at short notice to ensure grid stability and the successful integration of RES (Heffron et al. 2021; Palensky and Dietrich 2011).

Moreover, on the level of individual plant operation, a major challenge of RES consists in the highly volatile and even negative electricity prices (Fanone et al. 2013): Increasing the uncertainty of (future) income of RES-plant operators, such price characteristics directly challenge a viable operation of existing RES-plants and pose a possible barrier to further investments in new RES-plants.

Hence, research and practice intensively consider different possibilities to tackle challenges related to RES' intermittency: Among others, corresponding flexibility technologies comprise batteries, sector-coupling, grid expansion, and demand response (Heffron et al. 2020; Lannoye et al. 2015). Furthermore, research in the field of energy economics already discusses the approach of a local integration, i.e., the possibility to supply local flexibility by converting excess electricity on-site into goods, e.g., hydrogen, that may be stored or then sold on other nonelectricity markets (Glenk and Reichelstein 2019; Hosseini and Wahid 2016).

With respect to the development of a sustainable energy system with sufficient flexibility, research reflects the crucial role of Information Systems (IS), constituting the fields of Energy Informatics (EI) and Green IS (Buhl and Jetter 2009; Goebel et al. 2014; Watson et al. 2010). In this context, there exists a wide-ranging research stream dealing with the energy consumption of data centers (DC) and with the question how DCs can be designed more efficiently (Beloglazov et al. 2011; Pedram 2012). This includes (technical) literature concerning an efficient DC operation and a corresponding design. Moreover, this research stream also includes conceptual literature that elaborates on benefits of using DCs for the whole electricity system, e.g., by supplying flexibility through a participation in Demand Response (DR) programs. Another example relates to a spatial distribution of DCs and corresponding flexibility (Klingert 2018; Shi et al. 2016). In this context, Fridgen et al. (2017) discuss the idea of utilizing spatially distributed DCs to effectively supply flexibility by spatial load migration of computational power. Moreover, related literature already introduces the local combination of DCs and RES-plants (Ahmad et al. 2019; Goiri et al. 2013). However, this literature puts DCs at the core of research and mainly aims for lowering the electricity bill and the carbon-footprint of a DC. Thus, it lacks the ability to address the challenges of the development of a sustainable energy system with respect to a viable future operation of RES.

As highlighted above, to address the challenges of future energy systems, research needs to focus on an appropriate implementation and operation of RES-plants. Hence, - and in contrast to existing literature on DCs - our work puts the RES-plant at the core of our research and reflects on energy-intensive DCs as a means to contribute to a viable operation of and investment in RES-plants. We note that there are first companies, e.g., WindCORES, which integrate RES-plants and DCs in reality. However, the RESplant and the DC are predominantly not operated by the same company (Moss 2018), while the theory behind these first real-world examples is still missing. So far and to the best of our knowledge, research does not consider the approach of a local integration of RES-plants and electricity conversion into computing power (with respect to an IS-application) with the aim of increasing the economic viability of an RES-plant operation. Hence, we pose the following research question in the light of EI:

How can the integration of an intermittent RES-plant and a computationally intensive, energy-consuming DC yield an increased Net Present Value compared to a stand-alone RES-plant?

In line with Gholami et al. (2016), our paper constitutes application-oriented IS research that addresses the two challenges, namely the need for additional flexibility in the future electricity system and an economically viable operation of RES-plants. Hereby, we refer to the concept of integrated energy systems (IES), in general consisting of at least two plants, one of which is an energy consumer and the other an energy supplier (Bai et al. 2016). Following Bai et al. (2016), who provide an optimization model for an operation of gas-electricity IES, in this paper we analyze the impact of an IES - consisting of an RES-plant and a temporally flexible DC application - on the economic viability of an RES-plant using two exemplary use-cases. Within our IES, the RES-plant generates electricity that may either be sold on a corresponding electricity market or consumed locally within the IES by the DC. We reflect that an increasing Net Present Value (NPV) of the RES-plant within an IES may lead to increasing investments in RESplants, and can, therefore, be considered as a means to promote new RES-plants.

We note that the NPV of the IES can be increased by a variety of use-cases for the integrated plant, ranging, e.g., from (training) Machine Learning (ML) algorithms by cloud-computing DCs to (computerized) batch production of physical goods. However, we are also aware of the fact that the production of physical goods may be associated with a higher complexity when compared to a DC use-case. To illustrate the applicability of our approach, we therefore 
evaluate it with real-world data for two use-cases: While also providing the basis for future research in the context of IESs, in this paper we exemplarily reflect an integrated DC (1) as instances for training ML algorithms (here: Amazon Web Services (AWS)), and (2) for mining cryptocurrencies (here: Bitcoin). Hence, the objective of this paper is the development and quantitative evaluation of an economic model that considers an optimal investment decision into an IES using the NPV. To the best of our knowledge, an IES has neither been modeled nor quantitively evaluated as (1) opportunity to increase investments in RES-plants in times of volatile electricity prices and (2) as a supplier of energy flexibility in the light of EI. Moreover, we note that our model may also be of high relevance for RES-plant operators whose RES subsidy programs expire in the near future - as is, for example, the case in Germany where subsidies for $45 \mathrm{GW}$ of wind capacity have expired in 2020 (Friedemann 2018).

Our work contributes in various ways to research and practice: We build on (1) research on optimizing costs of DCs, on (2) research on Green IT, i.e., the environmentally friendly and resource-saving use of IT throughout its entire life cycle, and on (3) research on Green IS, i.e., using IT to increase sustainability in various fields. We are the first to introduce the approach of integrating RES-plants and DCs to increase the economic viability of RES-plants, and our evaluation illustrates that this approach is applicable in practice. Additionally, we contribute to IS research on energy flexibility, see e.g., Kahlen et al. (2014), Fridgen et al. (2016), and Keller et al. (2020). Moreover and following Watson et al. (2010), our IES provides the opportunity to use flow networks more efficiently as it is able to shift energy demand and, in this way, to supply local flexibility.

The structure of our paper is as follows: We provide relevant background for our research in Sect. 2. In line with the research cycle proposed by Meredith et al. (1989), Sect. 3.1 introduces our methodology while we develop and describe our economic model in Sect. 3.2. Concerning our evaluation, we discuss the applicability and relevance of our use-cases in Sect. 4. Then, Sect. 5 describes the data used for the evaluation and discusses corresponding results. Section 6 highlights the contribution of our paper, and Sect. 7 finally concludes, providing limitations and an outlook for further research.

\section{Related Literature and Background}

In addition to the literature mentioned in the introduction, we identify the following four research streams in academic literature that provide background for our analysis of integrating an intermittent RES-plant and a DC: EI, DCs, IESs, and energy flexibility.

Regarding EI, Watson et al. (2010) propose the field of EI that aims to implement a sustainable energy system by "analyzing, designing, and implementing systems to increase the efficiency of energy demand and supply systems" (Watson et al. 2010, p. 24). In this light, our paper analyzes both, the RES-plant and the integrated DC, as a part of a flow network where both parts constitute sensitized objects that are adaptable with respect to their electricity demand and supply (Watson et al. 2010). The recent streams of EI combine - as also highlighted in the call for this special issue - "the perspectives of electrical engineering, energy economics, and information technology" (Staudt et al. 2019). This is in line with Zhang et al. (2018), who state that EI analyzes various digital technologies and "their applications in the energy sectors" to tackle energyrelated challenges, see, e.g., Förderer et al. (2018) or Holly et al. (2020). Literature in this field finds that the intelligent management of DCs can introduce positive effects on the stability of such flow network and offer appropriate economic incentives (Thimmel et al. 2019). This is also closely related to the prevalent idea in IS research of ITenabled transdisciplinary sustainable business transformations, according to Elliot (2011), who proposes the idea that EI can help to lower humans' ecological impact through research on these complex phenomena. Zhang et al. (2011a) state that there are diverse opportunities to contribute to EI goals and thus motivate the need for and development of a strategic framework to effectively implement those. This is in line with EI researchers, who highlight both, the responsibility of IS research and corresponding opportunities in the near future (Buhl and Jetter 2009; Goebel et al. 2014). Therefore, our work contributes to EI research by reflecting a DC as an enabler for a more viable operation of RES-plants, which may, in turn, foster a sustainable transformation.

Regarding DCs, we already mentioned the wide-ranging research stream on energy consumption of DCs in our introduction. While research on the operation of DCs has focused on increasing their performance for decades, reducing energy costs gained more attention in the last years due to rising electricity prices (Beloglazov et al. 2011). As DCs are expected to account for about $20 \%$ of total electricity demand in 2030 (Jones 2018), research analyzes the question of how to make DCs more energyefficient in various ways (Pedram 2012). Such ways include, e.g., technical aspects of DCs redundancy architecture and workload prediction, approaches to use heat generated by the DC, or the participation of DCs in DRprograms (Kliazovich et al. 2013; Klingert 2018; Shi et al. 2016; Shuja et al. 2012). The ability to take part in DRprograms is, of course, dependent on the level of flexibility 
the DC is able to provide with respect to Service Level Agreements (SLAs) deadlines (Keller et al. 2020). Vieira et al. (2015) distinguish between three levels of flexibility handling DC services requests: (i) "fixed-time requests “ (no flexibility), (ii) "floating-time requests " (partly temporally flexible, e.g., interruptible), and (iii) "variable-time requests" (temporally flexible). Overall, current literature on energy-efficient DCs seems to be focused on lowering the electricity bill and the carbon-footprint of a DC.

Regarding (renewable) IESs, literature specifically addresses two streams. On the one hand, IESs play an important role in remote areas where reliability is important in the subsystem (Kanase-Patil et al. 2010). On the other hand, storage options for an efficient use of RES offer new prospects for IESs, which are especially discussed with respect to electricity battery storage (Connolly et al. 2012) and power conversion in Power-to-X plants (Glenk and Reichelstein 2019). Research suggests that Power-to-X plants converting electricity into a storable good like hydrogen or fuel may play an important role in future energy systems with their property to store electricity and use it in a flexible manner (Bai et al. 2016; Glenk and Reichelstein 2020). Within the energy research community, this research stream is also sometimes referred to and considered using the term smart energy systems (Lund et al. 2017). To the best of our knowledge, we are the first to present a model and an evaluation for an integration of an RES-plant and a DC.

Finally, regarding energy flexibility, research considers the concept of DR as a possible subset of Demand-Side Management and as a possible key element for tackling the challenge of grid stability for decades (Gellings 1985; Palensky and Dietrich 2011). Here, literature defines DR as the adaption of a load profile given, e.g., time-varying electricity market price signals (Palensky and Dietrich 2011). In this way, DR is a form of energy flexibility on the demand side (Haupt et al. 2020). Research repeatedly stresses the crucial role of IS for an efficient DR (Fridgen et al. 2020; Kahlen et al. 2018; Körner et al. 2019). Consequently, also IS research addresses the topic of load shifting. For example, Fridgen et al. (2016) assess the value of IS-enabled flexibility on the demand side, with a focus on electric vehicles. Gelazanskas and Gamage (2014) further elaborate on what information is needed to decide on specific DR measures. IS research also analyses how DR can be used to gain a financial advantage in various markets, e.g., on the electricity spot market (Jäckle et al. 2019). In the light of energy flexibility, DR may, therefore, help to increase the overall efficiency of an energy system, while at the same time reduce the cost of energy demand for consumers (Paulus and Borggrefe 2011). Against this background, our work contributes to this research stream by illustrating that an IES supplying flexibility is applicable and economically viable.

\section{Methodology}

\subsection{Methodological Approach}

To answer our research question, we follow the research cycle proposed by Meredith et al. (1989) that is widely used in IS research (Banz et al. 2016; Bürger et al. 2017). According to Meredith et al. (1989), model development should build on a research cycle consisting of three stages, namely the description, the explanation, and the testing stage. Accordingly, we develop a model that describes investment decisions in the IES and the optimal usage of the IES in Sect. 3.2 (also cf. Appendix A; available online via http://link.springer.com). Our model is based upon analytical modeling, as we assume a rational utilization of the IES (Meredith et al. 1989). To test our model, we evaluate it with real-world data in Sect. 5. In the following, we consider all three stages of the research cycle in more detail.

Meredith et al. (1989) state that the description stage is essential for model development as it characterizes the examined system. In line with such approach, we introduce and locate our IES into relevant fields of research that we identify in the literature (Sect. 2). Furthermore, we describe how the IES relates to similar technological systems in research, especially with respect to Power-to-X plants.

The explanation stage is characterized by developing the causal structures or complex relationships of a system. We constantly shift backward and forward between the description and the explanation stage in Sect. 3.2, as new aspects of the examined system are first described and then analyzed, as suggested by Meredith et al. (1989). In the light of Meredith et al. (1989), our analysis classifies as rational and artificial in analyzing the operation of an IES. We do so by conducting formal deductive quantitative modeling in Sect. 3.2. Our model assumes an investor, who acts as an economic agent that chooses the investment in the respective plants maximizing the NPV (Hirshleifer 1958). Building the basic framework for our model, we utilize the approach presented by Glenk and Reichelstein (2019), who identify an optimal investment decision into an IES consisting of an RES-plant and a Power-to-Gas plant. Subsequently, in line with Meredith et al. (1989), we illustrate the impact of our IES on promoting RES-plants.

In the testing stage, we examine the identified model along with a more detailed description of the situations that the testing is based on (Meredith et al. 1989). We begin the testing stage in Sect. 4 by describing how the application of 
AWS instances for ML and Bitcoin mining fits the examined relationships and stating the specific assumptions for the testing. We then quantitively apply our model in line with Taylor (2005) and describe the results in Sect. 5. Subsequently, we discuss the results in light of our RQ and illustrate the contributions of our paper.

\subsection{Model Development}

Based on the methodological approach described above, we first introduce the setup of our IES. We then briefly define the most relevant variables/parameters and derive the mathematical representation for an optimal investment decision. Figure 1 depicts the specific setup of the IES. The RES-plant (1) generates electricity that is either sold on the electricity market (2) or consumed within the IES by a DC (3). The DC thus consumes either electricity bought from the electricity market or electricity generated within the IES to execute computations, which are then compensated for by an external market (4). The IES itself consists of (1) and (3); hence the IES's system border relates to the connections between the IES and the respective markets (2) and (4). The relevant electricity market referred to in this work is the electricity spot market.

The objective of our model is to maximize the NPV of an investment in an IES based on the capacity investment decisions for the RES plant $k_{e}$ and the DC $k_{D C}$ (cf. detailed variable overview in Appendices A and B). We note that our model is based on previous work from the energy economics community, especially on the work of Glenk and Reichelstein (2019) and Glenk and Reichelstein (2020). We broaden the scope of application of their model, e.g., being applicable to real-world IS cases: we expand the model by temporally varying efficiency factors and output price determinants that account, for example, for the specifics of DC hardware and DC operation (cf. Appendix A).

We refrain from detailing out the model development step by step but instead give an overview on the overall model (see Appendix A for detailed model development).
The overall operation of the IES is split into four operation modes, which base on the comparison of the economic input factors, namely: the electricity selling price $p_{s}(t)$, the electricity buying price $p_{b}(t)$, and the conversion value of utilizing electricity in the DC $C V_{D C}(t)$. The operation mode describes how to optimally utilize the IES given the input factor prices and, thus, corresponds to the behavior of a rational operator. Based on the specific operation mode, the effect on the electricity grid may change when the IES shifts from a net supplier to a net consumer. We note that the four operation modes are not sequential, and hence, there is no fixed order of their occurrence. The four operation modes are described as follows and are illustrated in Fig. 2:

- Operation mode 1: The DC is idle as electricity prices are too high to operate the DC economically. The RESplant operates at full capacity and sells the generated electricity on the electricity market. This may reflect times, when there is overdemand for electricity and when there are low values for utilizing electricity in the DC. Therefore, the following relation holds: $p_{b}(t) \geq p_{s}(t) \geq C V_{D C}(t) \geq 0$.

- Operation mode 2: The DC utilizes electricity generated by the RES-plant as the utilization ensures a positive contribution margin, and additional DC capacity remains idle, as an operation with bought electricity is not economically viable. We have the following conditions: $p_{b}(t) \geq C V_{D C}(t)>p_{s}(t) \geq 0$.

- Operation mode 3: The DC operates at full capacity utilizing both the electricity generated by the RES-plant and additional electricity bought from the market. The following condition characterizes mode 3: $C V_{D C}(t)>p_{b}(t) \geq p_{s}(t) \geq 0$.

- Operation mode 4: The DC operates at full capacity utilizing electricity bought from the electricity market, while the RES-plant is idle. The operator is compensated for electricity bought from the electricity market (negative electricity prices), which implies that external
Fig. 1 Integrated energy system. (Adapted from Glenk and Reichelstein (2019))

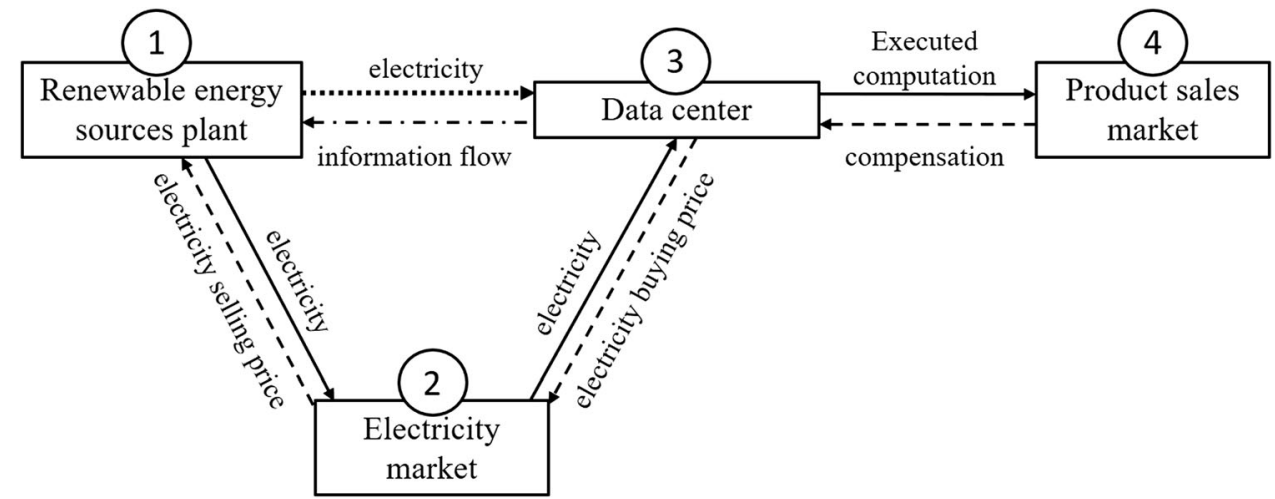




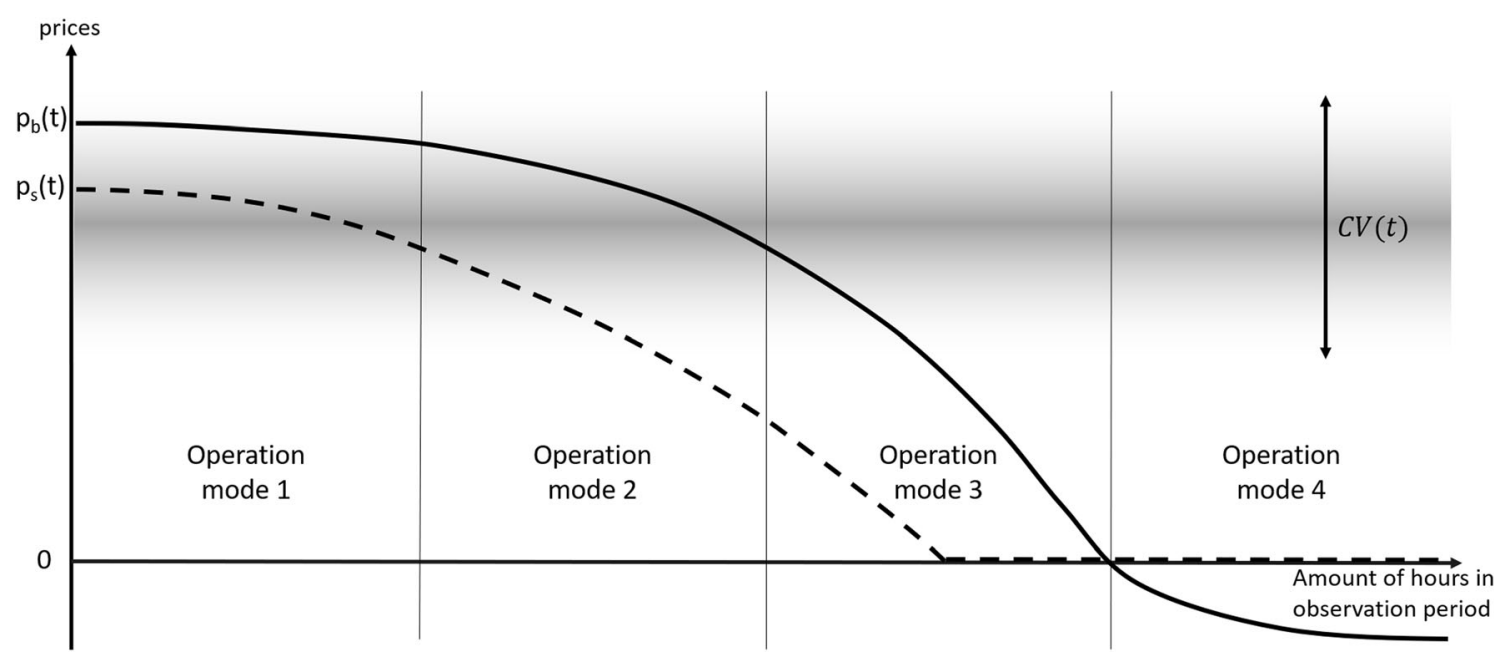

Fig. 2 Operation modes of the IES: Four different operation modes

electricity is utilized idling the RES-plant. The following relation holds: $C V_{D C}(t) \geq p_{s}(t)=0>p_{b}(t)$.

Based on these operation modes, the NPV of an IES as our objective function writes as follows (bars indicate a variable's mean; see Appendices A and B for further details):

$$
\begin{aligned}
N P V\left(k_{e}, k_{D C}\right)= & (1-\alpha) \cdot L \cdot\left[\left(\Gamma^{s} \cdot \bar{p}_{s}-L C O E\right) \cdot \overline{C F} \cdot k_{e}\right. \\
& +\left(\bar{p}_{b+}-\bar{p}_{b}-L F C C P\right) \cdot k_{D C} \\
& \left.+\left(\bar{p}_{+}-\bar{p}_{s}\right) \cdot z\left(k_{e}, k_{D C}\right)\right]
\end{aligned}
$$

The parameter $\alpha$ accounts for the operator's tax factor, $L$ represents a levelization factor, $\Gamma^{s}$ gives the deviation of input factors from their mean, $L C O E$ represent the levelized cost of electricity of the RES-plant, $L F C C P$ describe the levelized fixed cost of computing power, and $z\left(k_{e}, k_{D C}\right)$ is an auxiliary variable taking into account the respective capacities of the two plants, whereas $\bar{p}_{b+}$ and $\bar{p}_{+}$constitute price helper variables (a detailed description can be found in Appendices A and B).

The above equation reflects the stand-alone values of the specific parts of the IES by its first two terms as well as the synergistic value by the last term. Thus, the last term in the above equation allows us to state that the integration of an energy-intensive DC may well increase the NPV of an RES-plant as a part of the IES. The synergistic value is based on the fact that costs, e.g., transmission and storage costs, associated with the consumption of electricity from the market may be avoided. This is in line with the findings of Glenk and Reichelstein (2019) since these costs may be identified as the difference between $p_{b}(t)$ and $p_{s}(t)$ in operation mode 3 . Besides, the consumption of the DC increases as it also operates economically viable, if $p_{b}(t) \geq C V_{D C}(t) \geq p_{s}(t)$ holds in operation mode 2 . Hence, the above objective function already illustrates that investments in IESs, and therefore in RES-plants, may increase when integrated with a DC.

\section{Machine Learning and Cryptocurrency Mining as Use-Cases}

In the testing stage of our methodological approach, we evaluate our model with real-world data. Our IES may be applicable for a variety of use-cases, i.e., the plant that is to be integrated with the RES-plant may take a wide variety of different forms. These forms may range from production plants that convert electricity into physical goods to more IS-related forms, such as the conversion of electricity into computational power by a DC. With respect to the latter, we evaluate two specific use-cases that differ concerning their ratio between electricity input and product sales price, namely AWS (on-demand) instances for training ML algorithms and the mining of Bitcoin. While for these specific use-cases this ratio is much higher for Bitcoin mining as compared to AWS instances, we note that this may result from distorted (high) prices for using AWS instances. In this context, recent trends within the ML industry may lead to electricity costs becoming much more relevant for training ML algorithms (Sze et al. 2017). However, we note that today's AWS on-demand prices do only depict a relatively small ratio between electricity input and product sales price. Moreover, we note that SLAs may prevent the operator from idling the DC because of direct costs (due to SLA breaches) or indirect costs (due to lower customer satisfaction as a result of downtimes). However, regarding our evaluation, we consider the two use-cases to execute"variable-time requests" that may be shifted temporally in line with Keller et al. (2020) and Vieira et al. 
(2015). In the following, we give some more details on the two exemplary use-cases.

\subsection{Machine Learning}

$\mathrm{ML}$ - as a subset of artificial intelligence - provides entities with the possibility to compute human-like decisions by algorithms being able to produce knowledge by generalizing from examples, i.e., relations in exemplary data (Domingos 2012; Kratsch et al. 2020). The field has grown new interest over the past years in both, research and practice. A variety of computing algorithms exist that "learn" a new model based on an existing data set, e.g., to predict unknown data. This utilization of computing power also fits the setup of an IES as the learning needs not to take place at a specific time but may instead be shifted based on external market signals, in this context, specifically electricity market prices. Hence, we reflect it as temporally flexible in the sense of Vieira et al. (2015) which may be some simplification with interesting future research opportunities. Furthermore, research critically evaluates the increasingly high demand for ML use-cases and the corresponding energy demand (Jobin et al. 2019). AWS is the largest operator of cloud computing capacity and offers a variety of computing instances that are specifically designed to run ML applications. Therefore, its setup may serve as a use-case for an evaluation of our work.

\subsection{Bitcoin Mining}

Bitcoin mining constitutes the process of creating Bitcoins as well as validating transactions within the Bitcoin system (Nakamoto 2008). In order to be allowed to add a new block to the blockchain, a network participant must prove that the user has solved the according hashcash. A hashcash constitutes a cryptographic problem that is designed to be arbitrarily difficult to solve; if a solution is found, it can easily be verified whether the provided solution is correct or not. The only opportunity to solve a hashcash is that a computing machine randomly tries possible answers until the right one is met (Narayanan and Clark 2017). This process makes Bitcoin mining extraordinarily energy-intensive (Sedlmeir et al. 2020). However, we note that not all Blockchain applications may solely be regarded as energy-intensive consumers (Albrecht et al. 2018). For example, Nieße et al. (2018) reflect Blockchain as a technology to manage parts of the energy system by introducing a Blockchain-based system for congestion management. Moreover, for example, Utz et al. (2019) propose a Blockchain-based smart contract system for shared energy assets, while $\mathrm{Wu}$ and Tran (2018) review several Blockchain applications, e.g., for carbon emissions certification and trading. Regarding our evaluation, Bitcoin mining is not only implementable in practice, but the Bitcoin price also allows for an immediate price determination for the product corresponding to the energy input. Additionally, the operation of Bitcoin mining may be time-independent, i.e., adjustable to electricity generation or electricity prices without consumption catch-up effects. Thus, Bitcoin mining is utilized as a second evaluation case.

\section{Results and Implications}

\subsection{Description of Data and Assumptions}

Both use-cases are evaluated using real-world data from the German electricity market of the latest available three years 2016-2018 (see Appendix C, D). The German market serves as a relevant use-case given two reasons. First, there is a high share of intermittent RES on the German electricity market already today, resulting in quite volatile price patterns. Second, with respect to Germany's subsidy programs, the first government-subsidized RES-plants will phase out soon, creating a new market environment that may challenge the further operation of these plants. Therefore, we consider a wind power station in Germany as an exemplary RES-plant, and use the electricity spot price (intraday) for the German price region as the price for electricity sold on the electricity market $p_{s}(t)$. However, we note that the decision concerning the market(s) to address is itself a complex task. Our IES may also be able to operate in long-term markets, e.g., by Power Purchase Agreements, and short-term markets, e.g., in control energy markets. Also, hybrid solutions may be possible, where parts of the generated energy are traded at different markets. As a starting point, we consider the spot market which gives important price signals for plant operators. Regarding the purchase of electricity, $p_{b}(t)$, we assume a fixed surcharge based on industry electricity purchase (Glenk and Reichelstein 2019).

Regarding the ML-case, we additionally assume a DC output price in line with the publicly available on-demand utilization prices for ML instances provided by AWS (see Appendix C). We calculate electricity usage and costs based on the energy consumption of the associated hardware stack, including the respective investments. To incorporate overhead server energy consumption, i.e., cooling and memory, we add a surcharge of $70 \%$ on the DC's processing chip energy consumption in line with Dayarathna et al. (2016). As (i) the specific cost structure and the respective energy consumption of an AWS server stack is not publicly available, and (ii) the modeling of highly specific costs, e.g., costs for switching on and off or 
stand-by costs of the idle DC, yields a high model complexity due to discrete decisions (Dayarathna et al. 2016), we simplify these costs and assume that they are included in the fixed operating costs. In line with Fridgen et al. (2017), we further assume that the energy consumption of the DC is proportional to its load operated. Considering research and practice, we note that there are several promising approaches demonstrating and further improving the proportionality between a DC's processing capacity and its load (Gandhi et al. 2010; Ganesh et al. 2013; Lin et al. 2013; Tolia et al. 2008; Whitney and Delforge 2014). However, we also note that this assumption may limit the accuracy of our numerical results but does not affect their general explanatory power. To address this issue, we conducted sensitivity analyses regarding the input factors, e.g., costs for equipment, especially overhead costs, or energy consumption of this equipment, (for example, of cooling servers). Some DCs also utilize significant shares of electricity when they are idle, which is why we increased fixed operating costs by 50\%, 100\%, and 200\%. The operation modes and corresponding results presented hereinafter do not change significantly (cf. Sect. 5.2 and 5.3), whereas the NPV of the investment as well as the optimal DC capacity shrinks due to increased costs.

Regarding the BC-case, we evaluate the model with Bitcoin price data and the respective mining network characteristics, i.e., mining difficulty, block reward, and transaction fee, based on publicly available sources (see Appendix D). We base our assumptions regarding costs and computational power on mining hardware that was available at the beginning of the observation period to ensure coherent results. We maintain the assumption of proportionality between the DC load and the corresponding energy consumption as stated above.

Figure 3 depicts the conversion values and electricity prices used in our evaluation. The dots depict the conversion value range of the Bitcoin mining plant. The hours within the observation period of three years, i.e., 26,304 h, limit the abscissa in Fig. 3. The level of the conversion value of Bitcoin mining $C V_{B C}(t)$ is temporarily above, below, or between the prices for buying electricity $p_{b}(t)$ (see the drawn through line) and the price for selling electricity $p_{s}(t)$ (see the dashed line), which illustrates the different operation modes of IES operation an illustrates that the four operation modes of our model (cf. Figure 2) indeed occur within our real-world evaluation case. We note that the conversion value $C V_{M L}$ based on the constant on-demand price for AWS ML instances is above the prices for buying and selling electricity at all times (represented in Fig. 3 as dashed-dotted line).
5.2 Results for an Investment in Stand-alone RESPlants and DCs

When assessing the NPV of a stand-alone DC (without an RES-plant), the variable $k_{e}$ that describes the capacity of the RES-plant is set to zero, implying that the DC can only consume electricity that is bought from the electricity market. The left subfigure in Fig. 4 depicts the NPV of an investment in a stand-alone ML-DC, depending on the chosen capacity $k$ of the DC. The NPV proportionally increases (ML-case with capacity $k_{M L}$ ) or falls (BC-case with capacity $k_{B C}$ ) with increased investment. This is mainly based on two facts. First, no synergies within an IES can be used, as electricity can only be bought from the market. Second, our model suggests that investments and operating costs behave proportionally to the invested capacity. In our evaluation setting, the optimal decision of an investor is to fully invest in the ML capacity $\left(k_{M L}=1\right)$ but not at all in the mining plant $\left(k_{B C}=0\right)$. The latter is due to the fact that the price to purchase electricity on the market is too high to recoup the capacity investment, although the DC is active in $35 \%$ of the considered time periods. This finding is in line with the low amount of Bitcoin mining in Germany (Willms 2019), and also persists - given the results of our sensitivity analyses - if the fixed operating costs are increased. The optimal capacity of the respective DC remains either 1 in the ML-case or 0 in the BC-case. Based on the used data, the NPV of a standalone RES-plant $N P V_{k_{e}}$ is positive in our evaluation setting. This analysis is generally independent of the capacity of the plant as indicated in the right subfigure of Fig. 4, as the slope of the NPV function is constant. The constant slope depicts an idealized setting since a continuous construction and dismantling of the capacities of DCs as well as RESplants may not be possible in reality.

\subsection{Results for an Investment in an Integrated Energy System}

For the investment in an IES, we assume that the RESplant either sells its electricity to the electricity market or the electricity is locally consumed in the integrated DC. As we already described above, the NPV of the stand-alone ML-DC may be positive (due to high ML conversion values). Our results thus illustrate that the NPV of an IES, consisting of an RES-plant and a ML-DC, yields a positive NPV alike. The IES does not feed-in electricity into the grid at any time, but it uses the generated electricity locally for the integrated ML-DC. This effectively results in the absence of operation mode 1 of the model. It corresponds to expectations from real-world observations, as DC services are normally not deactivated by providers due to high electricity costs. The result for the ML-case demonstrates 


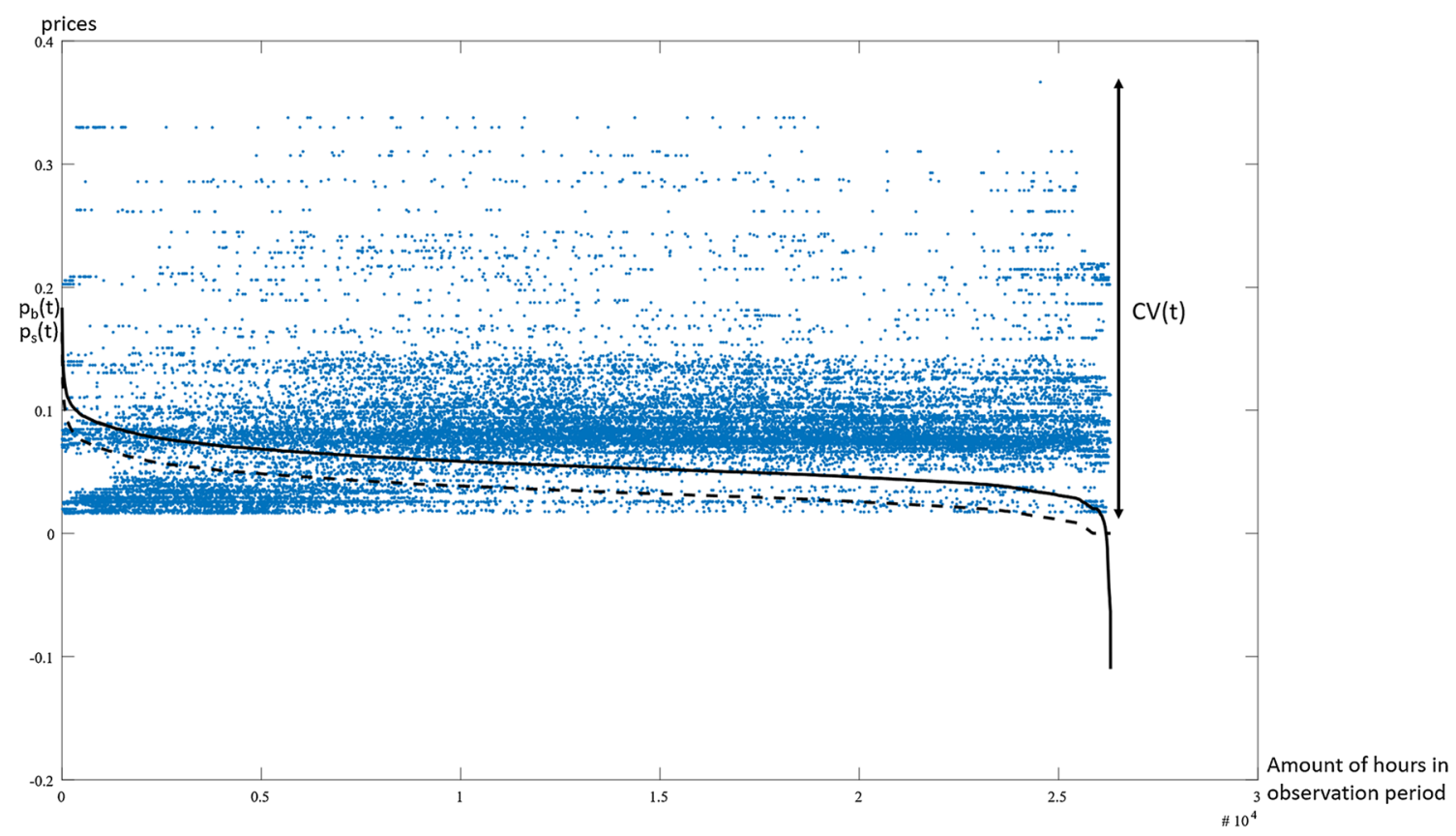

Fig. 3 Conversion values and electricity prices of the IESs
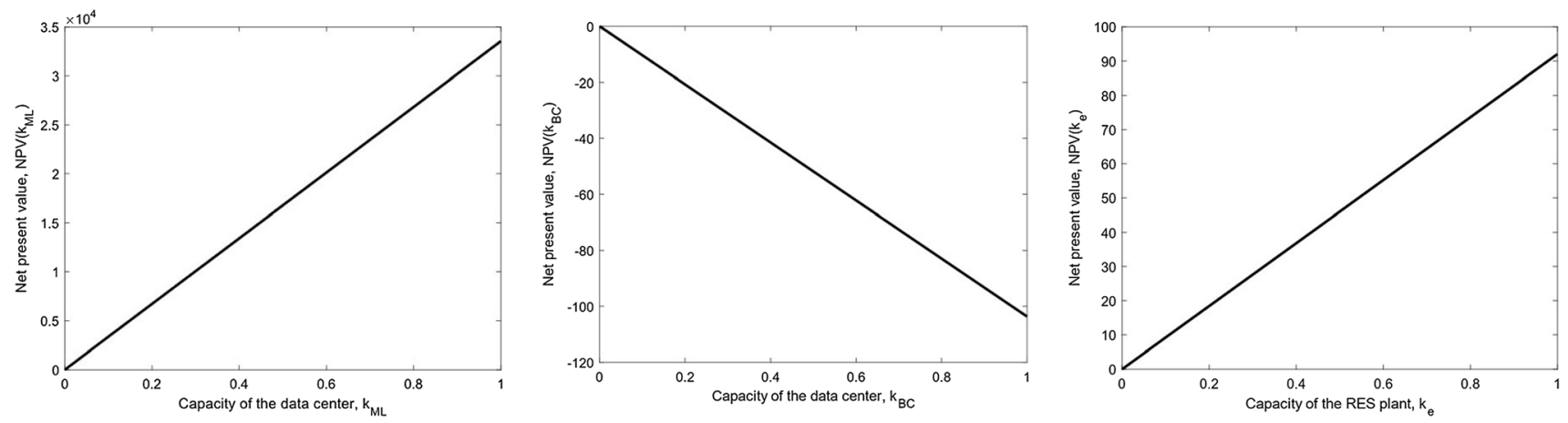

Fig. 4 Depiction of the NPV of the stand-alone plants: ML-DC (on the left), Bitcoin mining DC (in the middle), and RES-plant (on the right)

that the integration indeed yields synergistic effects, i.e., the NPV of the IES is higher than the sum of the NPV of the two stand-alone plants. This may effectively reduce the electricity bill for operating the energy-intensive ML application. Furthermore, the utilization of the RES-plant may increase as its generated electricity may also be used in the ML-DC at times when the selling price for electricity drops below 0 . This effect is accompanied by an increase in the share of RES that is utilized within the ML-DC in comparison to the stand-alone case (utilizing only market electricity), resulting in a decrease of the DC's carbonfootprint. The conducted sensitivity analyses suggest that the optimal investment size remains the same, whereas the NPV of the IES is lower in case of higher fixed costs, e.g., the NPV is reduced by $9 \%$ if the fixed costs are increased by $100 \%$. The synergistic value persists as well.
As the stand-alone Bitcoin mining plant yields no positive NPV in our evaluation setting, an investment in Bitcoin mining capacity larger than the capacity of the RESplant cannot maximize the NVP of the IES. Thus, if we normalize the capacity of the RES-plant $k_{e}$ to 1 , the optimal investment in the Bitcoin mining plant $k_{B C}$ must lie in the closed interval $[0,1]$. In contrast to the evaluation of each stand-alone case, the left subfigure in Fig. 5 shows a concave NPV function for the IES. This concavity implies that synergies between the two parts of the IES exist as identified in our model. In particular, our results illustrate that the NPV of the IES has a single optimal capacity of $k_{D C}=0.45$. This implies that the peak capacity of the mining plant equals $45 \%$ of the peak capacity of the RESplant. In this way, our evaluation finds that the NPV of the IES is $32 \%$ higher than the stand-alone NPV of the RESplant. In comparison to the stand-alone case, the operation 

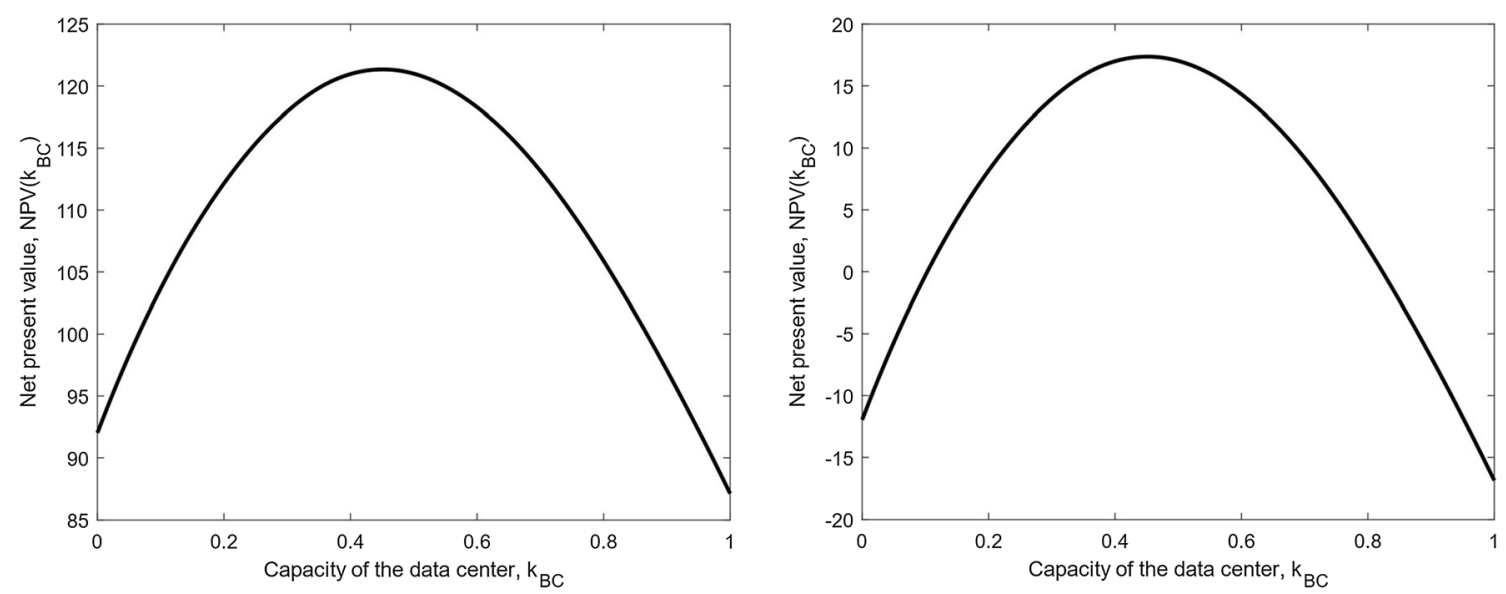

Fig. 5 Depiction of NPV of the IES that consists of an RES-plant and a Bitcoin mining plant (on the left) and the NPV of the same IES assuming higher maintenance costs for the RES-plant (on the right)

of the IES changes significantly. The IES's inherent RESplant supplies $73 \%$ of the electricity that is consumed by the mining plant. The share of $73 \%$ RES supply is more than doubled, if compared to the German grid mix having an average of $35.1 \%$ of RES supply during the observation period (BMWi 2019). For this use-case, our IES may help to reduce the carbon-footprint of Bitcoin mining. Here, we also note that - as illustrated by Sedlmeir et al. (2020) other consensus mechanisms such as proof of stake or proof of capacity may help to reduce the carbon-footprint. Furthermore, the mining plant now operates $82 \%$ of the time, which constitutes a significant increase compared to the stand-alone mining plant (35\%). Overall, the IES is characterized by a net energy supply within the observation period: the RES-plant feeds-in $12 \%$ more electricity to the grid than the mining plant consumes. Overall, we find that $36 \%$ of the total energy generation of the RES-plant is fedin the grid. The mining plant consumes internal energy at low electricity prices, which indicate a high (over-) supply of electricity on the market. Anyhow, the underlying data suggests a negative correlation $(\rho=-0.33)$ between RES generation and the price for selling electricity at the market $p_{s}(t)$, which is supported by existing research (Sáenz de Miera et al. 2008). Consequently, the mining plant consumes internally generated electricity when the opportunity cost for selling this electricity on the market is low and the (overall) amount of electricity that is fed into the grid is high. Hence, the IES may contribute to grid stability by locally using generated electricity instead of feeding it into the grid, i.e., by supplying (local) flexibility.

In the near future, there will also be settings, in which the specific stand-alone NPV of the RES-plant is negative, e.g., due to higher fixed maintenance costs for the RESplant at the end of the plant's lifetime RES-plant (Ziegler et al. 2018). We also find that in cases where the NPVs of both, the RES-plant and the DC, are negative, the optimal decision of an investor may be to invest in the IES. In other words, even if both parts of the IES cannot be operated economically viable on a stand-alone basis, the IES may be profitable. The subfigure on the right only depicts a shift of the NPV function (cf. vertical axes), as the synergies that stem from the integration of the two plants remain unaffected. The optimal investment in both cases is again $k_{D C}=0.45$ and even in the setting illustrated in the right subfigure we derive a positive NPV. We also note that this result supports the findings of Glenk and Reichelstein (2019), who analytically show that the synergistic value of an IES may outweigh the negative NPVs of both standalone plants. The conducted sensitivity analyses suggest that the optimal capacity may decrease if fixed costs are higher. For example, the optimal capacity may decrease to $k_{D C}=0.25$ if the fixed costs may be $200 \%$ higher. Such lower capacity further decreases the share of electricity used internally and consequently the synergistic value of the IES (then $41 \%$ ).

To sum up, both use-cases, the ML-case and the Bitcoincase, yield positive NPVs resulting in the promotion of RES-plants. Moreover, when integrated with an RES-plant, the Bitcoin mining plant is able to provide significant demand-side flexibility.

\section{Contribution}

Based on the modeling and evaluation in the previous sections, we summarize first research contributions of our work as well as first insights for practice and decisionmakers.

Concerning the contribution to IS research, our results build on research on optimizing energy costs of DCs, on research on reducing the carbon-footprint of DCs (Green IT), and on research on how to use IT-infrastructure to 
increase the sustainability of the energy system (Green IS) as described in Sect. 5. Moreover, our work contributes to the research stream on IS-enabled energy flexibility, see, e.g., Kahlen et al. (2014), Fridgen et al. (2016), and Keller et al. (2020). Our IES constitutes a new way of providing (local) energy demand-side flexibility. Such flexibility results from the operation mode of the IES reacting to electricity market signals, i.e., electricity prices; if market signals indicate that overall electricity feed-in is (too) high, i.e., electricity prices are low or negative, the IES's electricity will be used by the integrated DC and the overall amount of electricity in the system decreases. Our evaluation suggests that the more relevant electricity costs of the converted good are, as compared to its output price, the more sensitively the IES operates with respect to external electricity market signals (see Sect. 5). This may be of particular interest as recent trends suggest that the relevance of electricity costs for ML applications will increase significantly. Furthermore, we also contribute to IS-research and theory by building on the work of Watson et al. (2010). Our IES provides new opportunities for increasing the efficiency of flow networks as introduced by Watson et al. (2010), given that the IES supplies local flexibility by converting excess electricity on-site into computational power. In this sense, our approach may help to use flow networks more efficiently by implementing IS applications, e.g., an IES. In addition, both parts of our IES, the RESplant as well as the integrated DC, may constitute sensitized objects. In this context, our research also contributes to further developing use-cases for the concept of edge computing as the IES may shift computational power towards the edges of the network. This may be particularly relevant for research focusing on topics of sustainable edge computing ( $\mathrm{Li}$ et al. 2018). Moreover, we contribute to research by transferring approaches from outside the IScommunity, i.e., Glenk and Reichelstein (2019), into the field of EI. We develop an economic model for an IES that reflects IS cases in which the consuming part of the IES is a DC.

Our work is also highly relevant for practice and decision-makers when reflecting on the implementation of IESs. In our evaluation, we illustrate that the IES performs well for practical settings, e.g., for ML and for Bitcoin mining as examples for (energy-intensive) applications. In both cases, the IES has a positive NPV, i.e., the operation of the RES-plant and the DC within the IES is economically viable. We also analyze the situation where the NPV of a stand-alone RES-plant is negative, e.g., due to high fixed maintenance costs or due to the expiration of subsidy programs, resulting in a situation where a (further) operation of the RES-plant on its own may not be economically viable (Friedemann 2018; Ziegler et al. 2018). For such cases, our results illustrate that the NPV of the IES may be positive even if the NPV of both, the stand-alone RESplant and the respective DC, is negative. Moreover, as highlighted above, our work will also be increasingly relevant for companies that deal with ML applications, reflecting that energy costs for ML will increase within the next years, and its usage may be shifted temporally. In summary, as our IES has a higher NPV compared to the stand-alone plants, it may increase investments in RESplants by tackling uncertainties of RES-plant operators concerning income in time periods with low electricity prices. From an overall energy-system perspective, the RES generation could be promoted through a corresponding integration with an energy-intensive DC.

\section{Conclusion, Limitations, and Further Research}

In this paper, we present an economic model that illustrates how the integration of an RES-plant with an energy-intensive DC into an IES may increase the economic viability of an RES-plant operation. We evaluate our model by applying two use-cases, namely, ML and Bitcoin mining to make use of the DC. Our results illustrate that the NPV of the IES can be higher than the NPV of the stand-alone RES-plant as well as of a stand-alone DC. We argue that a higher NPV of an IES may promote investments in RESplants. Especially with respect to the prevalent negative correlation between RES generation and electricity market prices, the IES could tackle uncertainties for RES-plant operators concerning their income in times of low electricity prices. Moreover, we argue that our IES is also be able to contribute to grid stability by supplying flexibility. We also note that the DC - when used within the IES may consume a higher share of RES and thus distinctly reduce its own carbon-footprint. Overall, we conclude that our IES promotes the operation of RES-plants by integrating energy-intensive DCs.

Given our first results, we briefly sketch some limitations of our work. In general, our methodology in terms of application-oriented modeling inhibits limitations itself, including a simplification of a real-world application and the exclusion of specific contextual factors such as the need for a timely execution of computing services. These factors may be incorporated as SLA costs or deadlines that introduce additional constraints to the model at hand. Our evaluation use-cases may limit our results as they are based on specific economic parameters and assumptions that may differ when assessing other applications. For example, we base our ML-evaluation on several assumptions concerning the costs of operating a DC, however, the cost structure of AWS server stacks is not publicly available. Moreover, we simplify the economics of a mining plant in our evaluation; in particular, we assume that a large part of the DC has no 
recovery value at the end of the three-year term, whereas the future use in reality is rather complex. For example, the utilization of the mining processor may become obsolete due to future mining difficulties or new mining technologies. In such cases, the equipment may still well be utilized in application areas with lower electricity prices and therefore sold to other operators. In consequence, specific assumptions of our evaluation cases may not fit generic real-world applications, which may require a more detailed consideration of additional (technical) constraints of an IES operation.

Our work also provides various starting points for further research that may extend our approach, for example, by considering other markets or the interconnection between the IES and the grid in more detail. Here, research may address the above limitations by applying additional use-cases and corresponding markets, e.g., control energy markets. Reflecting and incorporating the value of addressing several markets with one IES may constitute the basis for the development of specific decision support systems for operators. Further research may also quantify the IES's contribution to addressing grid stability issues in full details. Moreover, further research may consider specific cost structures of DCs in all their particulars. With respect to further EI research, we suggest reflecting the role of edge computing in the light of consuming electricity locally as it inherently shifts electricity consumption towards the edges of a computing grid. Moreover, future work may also discuss relevant implications for policymakers, e.g., analyze whether and which kinds of subsidy programs for promoting RES-plants (that typically bear huge costs for the general public) are needed under consideration of concepts like IESs. Here, our first results suggest that the implementation of (new) subsidy programs, especially feed-in tariffs, may reduce synergistic effects of the IES. Feed-in tariffs generally entail higher opportunity costs for the operator of an IES when consuming the electricity within the IES. Against this background, our work may serve as a profound starting point for future research in the highly relevant field of EI.

Acknowledgements We gratefully acknowledge the Luxembourg National Research Fund (FNR) and PayPal for their support of the PEARL Project "P17/IS/13342933/PayPal-FNR/Chair in DFS/Gilbert Fridgen" that made this paper possible. We gratefully acknowledge the financial support of the Kopernikus-Project "SynErgie" by the BMBF - Federal Ministry of Education and Research, Germany and the Project supervision by the Project management organization Projektträger Jülich (PtJ).

Funding Open Access funding enabled and organized by Projekt DEAL.

Open Access This article is licensed under a Creative Commons Attribution 4.0 International License, which permits use, sharing, adaptation, distribution and reproduction in any medium or format, as long as you give appropriate credit to the original author(s) and the source, provide a link to the Creative Commons licence, and indicate if changes were made. The images or other third party material in this article are included in the article's Creative Commons licence, unless indicated otherwise in a credit line to the material. If material is not included in the article's Creative Commons licence and your intended use is not permitted by statutory regulation or exceeds the permitted use, you will need to obtain permission directly from the copyright holder. To view a copy of this licence, visit http://creativecommons. org/licenses/by/4.0/.

\section{References}

Ahmad S, Rosenthal A, Hajiesmaili MH, Sitaraman RK (2019) Learning from optimal: energy procurement strategies for data centers. In: Proceedings of the tenth ACM international conference on future energy systems, Phoenix, pp 326-330. https://doi. org/10.1145/3307772.3328308

Albrecht S, Reichert S, Schmid J, Strüker J, Neumann D, Fridgen G (2018) Dynamics of blockchain implementation: a case study from the energy sector. In: Proceedings of the 51st Hawaii international conference on system sciences, Waikoloa Village, Hawaii. https://doi.org/10.24251/HICSS.2018.446

Bai L, Li F, Cui H, Jiang T, Sun H, Zhu J (2016) Interval optimization based operating strategy for gas-electricity integrated energy systems considering demand response and wind uncertainty. Appl Energy 167:270-279. https://doi.org/10.1016/j.apenergy. 2015.10.119

Banz M, Grosswiele L, Huber J, Probst F (2016) More fans at any cost? Analysing the economic effects of the ratio of fans to nonfans in a customer portfolio considering electronic word of mouth. J Decis Syst 25(3):193-213. https://doi.org/10.1080/ 12460125.2016.1187545

Beloglazov A, Buyya R, Lee YC, Zomaya A (2011) A taxonomy and survey of energy-efficient data centers and cloud computing systems. Adv Comput 82:47-111. https://doi.org/10.1016/B9780-12-385512-1.00003-7

BMWi (2019) Anteil der Erneuerbaren Energien am Bruttostromverbrauch. https://www.bmwi.de/Redaktion/DE/Infografiken/Ener gie/anteil-erneuerbarer-energien-steigt.html. Accessed 28 Oct 2020

Buhl HU, Jetter M (2009) BISE's responsibility for our planet. Bus Inf Syst Eng 1:273-276. https://doi.org/10.1007/s12599-0090058-Z

Bundesnetzagentur (2019) Netz- und Systemsicherheitsmaßnahmen, Gesamtjahr und Viertes Quartal 2018. https://www.wind-ener gie.de/fileadmin/redaktion/dokumente/publikationen-oeffentlich/ themen/02-technik-und-netze/01-netze/20180621_Hintergrund_ Redispatch_und_Einspeisemanagement_AP_002_.pdf. Accessed 25 Oct 2020

Bürger O, Häckel B, Moser F (2017) Towards an optimal investment strategy considering fashionable IT innovations: a dynamic optimisation model. J Decis Syst 26:229-255. https://doi.org/10. 1080/12460125.2017.1314614

Connolly D, Lund H, Mathiesen BV, Pican E, Leahy M (2012) The technical and economic implications of integrating fluctuating renewable energy using energy storage. Renew Energy 43:47-60. https://doi.org/10.1016/j.renene.2011.11.003

Dayarathna M, Wen Y, Fan R (2016) Data center energy consumption modeling: a survey. IEEE Commun Surv Tutor 18(1):732-794. https://doi.org/10.1109/COMST.2015.2481183 
Domingos P (2012) A few useful things to know about machine learning. Commun ACM 55:78-87. https://doi.org/10.1145/ 2347736.2347755

Elliot S (2011) Transdisciplinary perspectives on environmental sustainability: a resource base and framework for IT-enabled business transformation. MIS Q 35(1):197-236. https://doi.org/ $10.2307 / 23043495$

Fanone E, Gamba A, Prokopczuk M (2013) The case of negative dayahead electricity prices. Energy Econ 35:22-34. https://doi.org/ 10.1016/j.eneco.2011.12.006

Förderer K, Ahrens M, Bao K, Mauser I, Schmeck H (2018) Modeling flexibility using artificial neural networks. Energy Inform. https://doi.org/10.1186/s42162-018-0024-4

Fridgen G, Häfner L, König C, Sachs T (2016) Providing utility to utilities: the value of information systems enabled flexibility in electricity consumption. JAIS 17(8):537-563. https://doi.org/10. 17705/1jais.00434

Fridgen G, Keller R, Thimmel M, Wederhake L (2017) Shifting load through space- the economics of spatial demand side management using distributed data centers. Energy Policy 109:400-413. https://doi.org/10.1016/j.enpol.2017.07.018

Fridgen G, Keller R, Körner M-F, Schöpf M (2020) A holistic view on sector coupling. Energy Policy 147:111913. https://doi.org/ 10.1016/j.enpol.2020.111913

Friedemann A (2018) Germany's wind energy mess: as subsidies expire, thousands of turbines to close. http://energyskeptic.com/ 2018/germanys-wind-energy-mess-as-subsidies-expire-thou sands-of-turbines-to-close/. Accessed 7 Nov 2020

Gandhi A, Gupta V, Harchol-Balter M, Kozuch MA (2010) Optimality analysis of energy-performance trade-off for server farm management. Perform Eval 67(11):1155-1171. https://doi. org/10.1016/j.peva.2010.08.009

Ganesh L, Weatherspoon H, Marian T, Birman K (2013) Integrated approach to data center power management. IEEE Trans Comput 62(6):1086-1096. https://doi.org/10.1109/TC.2013.32

Gelazanskas L, Gamage KAA (2014) Demand side management in smart grid: a review and proposals for future direction. Sustain Cities Soc 1:22-30. https://doi.org/10.1016/j.scs.2013.11.001

Gellings CW (1985) The concept of demand-side management for electric utilities. Proc IEEE 73(10):1468-1470. https://doi.org/ 10.1109/PROC.1985.13318

Gholami R, Watson RT, Hasan H, Molla A, Bjorn-Andersen N (2016) Information systems solutions for environmental sustainability: how can we do more? JAIS. https://doi.org/10.17705/1jais.00435

Glenk G, Reichelstein S (2019) Economics of converting renewable power to hydrogen. Nat Energy 4:216-222. https://doi.org/10. 1038/s41560-019-0326-1

Glenk G, Reichelstein S (2020) Reversible fuel cells: an economic analysis. SSRN J. https://doi.org/10.2139/ssrn.3567167

Goebel C, Jacobsen H-A, del Razo V, Doblander C, Rivera J, Ilg J, Flath C, Schmeck H, Weinhardt C, Pathmaperuma D, Appelrath H-J, Sonnenschein M, Lehnhoff S, Kramer O, Staake T, Fleisch E, Neumann D, Strüker J, Erek K, Zarnekow R, Ziekow H, Lässig J (2014) Energy informatics. Bus Inf Syst Eng 6:25-31. https://doi.org/10.1007/s12599-013-0304-2

Goiri Í, Katsak W, Le K, Nguyen TD, Bianchini R (2013) Parasol and GreenSwitch. ACM SIGPLAN Not 48(4):51-64. https://doi.org/ 10.1145/2499368.2451123

Haupt L, Körner M-F, Schöpf M, Schott P, Fridgen G (2020) Strukturierte Analyse von Nachfrageflexibilität im Stromsystem und Ableitung eines generischen Geschäftsmodells für (stromintensive) Unternehmen. Z Energiewirtsch 44:141-160. https://doi.org/10.1007/s12398-020-00279-5

Heffron R, Körner M-F, Wagner J, Weibelzahl M, Fridgen G (2020) Industrial demand-side flexibility: a key element of a just energy transition and industrial development. Appl Energy. https://doi. org/10.1016/j.apenergy.2020.115026

Heffron R, Körner M-F, Schöpf M, Wagner J, Weibelzahl M (2021) The role of flexibility in the light of the COVID-19 pandemic and beyond: contributing to a sustainable and resilient energy future in Europe. Renew Sustain Energy Rev. https://doi.org/10. 1016/j.rser.2021.110743

Hirshleifer J (1958) On the theory of optimal investment decision. J Polit Econ 66(4):329-352. https://doi.org/10.1086/258057

Holly S, Nieße A, Tröschel M, Hammer L, Franzius C, Dmitriyev V, Dorfner J, Veith EM, Harnischmacher C, Greve M, Masuch K, Kolbe L, Wulff B, Kretz J (2020) Flexibility management and provision of balancing services with battery-electric automated guided vehicles in the Hamburg container terminal Altenwerder. Energy Inform. https://doi.org/10.1186/s42162-020-00129-1

Hosseini SE, Wahid MA (2016) Hydrogen production from renewable and sustainable energy resources: promising green energy carrier for clean development. Renew Sustain Energy Rev 57:850-866. https://doi.org/10.1016/j.rser.2015.12.112

Jäckle F, Schoepf M, Töppel J, Wagon F (2019) Risk mitigation capability of flexibility performance contracts for demand response in electricity systems. In: Proceedings of the 27th ECIS, Stockholm \& Uppsala, Sweden. https://aisel.aisnet.org/ ecis2019_rp/175/. Accessed 7 Nov 2020

Jobin A, Ienca M, Vayena E (2019) The global landscape of AI ethics guidelines. Nat Mach Intell 1:389-399. https://doi.org/10.1038/ s42256-019-0088-2

Jones N (2018) How to stop data centres from gobbling up the world's electricity. Nature 561:163-166. https://doi.org/10.1038/d41586018-06610-y

Kahlen M, Ketter W, van Dalen J (2014) Balancing with electric vehicles: a profitable business model. In: 2017 IEEE custom integrated circuits. https://aisel.aisnet.org/ecis2014/proceedings/ track22/11/. Accessed 7 Nov 2020

Kahlen MT, Ketter W, van Dalen J (2018) Electric vehicle virtual power plant dilemma: grid balancing versus customer mobility. Prod Oper Manag 27(11):2054-2070. https://doi.org/10.1111/ poms. 12876

Kanase-Patil AB, Saini RP, Sharma MP (2010) Integrated renewable energy systems for off grid rural electrification of remote area. Renew Energy 35(6):1342-1349. https://doi.org/10.1016/j. renene.2009.10.005

Keller R, Häfner L, Sachs T, Fridgen G (2020) Scheduling flexible demand in cloud computing spot markets. Bus Inf Syst Eng 62:25-39. https://doi.org/10.1007/s12599-019-00592-5

Kliazovich D, Bouvry P, Khan SU (2013) DENS: data center energyefficient network-aware scheduling. Cluster Comput 16:65-75. https://doi.org/10.1109/GreenCom-CPSCom.2010.31

Klingert S (2018) Mapping data centre business types with power management strategies to identify demand response candidates. In: e-Energy '18: proceedings of the ninth international conference on future energy systems, Karlsruhe, pp 492-498. https://doi.org/https://doi.org/10.1145/3208903.3213521

Körner M-F, Bauer D, Keller R, Rösch M, Schlereth A, Simon P, Bauernhansl T, Fridgen G, Reinhart G (2019) Extending the automation pyramid for industrial demand response. Proc CIRP 81:998-1003. https://doi.org/10.1016/j.procir.2019.03.241

Kratsch W, Manderscheid J, Röglinger M, Seyfried J (2020) Machine learning in business process monitoring: a comparison of deep learning and classical approaches used for outcome prediction. Bus Inf Syst Eng, in print. https://doi.org/10.1007/s12599-02000645-0

Lannoye E, Flynn D, O’Malley M (2015) Transmission, variable generation, and power system flexibility. IEEE Trans Power Syst 30:57-66. https://doi.org/10.1109/TPWRS.2014.2321793 
Li W, Yang T, Delicato FC, Pires PF, Tari Z, Khan SU, Zomaya AY (2018) On enabling sustainable edge computing with renewable energy resources. IEEE Commun Mag 56(5):94-101. https://doi. org/10.1109/MCOM.2018.1700888

Lin M, Wierman A, Andrew LHH, Thereska E (2013) Dynamic rightsizing for power-proportional data centers. IEEE/ACM Trans Netw 21(5):1378-1391. https://doi.org/10.1109/TNET.2012. 2226216

Linnemann C, Echternacht D, Breuer C, Moser A (2011) Modeling optimal redispatch for the European transmission grid. In: Staff I (ed) 2011 IEEE Trondheim PowerTech. IEEE, Trondheim. https://doi.org/10.1109/PTC.2011.6019442

Lund H, Østergaard PA, Connolly D, Mathiesen BV (2017) Smart energy and smart energy systems. Energy 137:556-565. https:// doi.org/10.1016/j.energy.2017.05.123

Meredith JR, Raturi A, Amoako-Gyampah K, Kaplan B (1989) Alternative research paradigms in operations. J Oper Manag 8(4):297-326. https://doi.org/10.1016/0272-6963(89)90033-8

Moss S (2018) WindCores project deploys small data centers inside wind turbines: German company to use Fujitsu servers. https:// www.datacenterdynamics.com/en/news/windcores-projectdeploys-small-data-centers-inside-wind-turbines/. Accessed 2 Nov 2020

Nakamoto S (2008) Bitcoin: a peer-to-peer electronic cash system. https://bitcoin.org/bitcoin.pdf. Accessed 15 Oct 2020

Narayanan A, Clark J (2017) Bitcoin's academic pedigree. Commun ACM 60(12):36-45. https://doi.org/10.1145/3132259

Nieße A, Lehnhoff S, Troschel M, Uslar M, Wissing C, Appelrath H-J, Sonnenschein M (2012) Market-based self-organized provision of active power and ancillary services: an agent-based approach for smart distribution grids. In: 2012 complexity in engineering COMPENG, pp 1-5, Aachen. https://doi.org/10. 1109/CompEng.2012.6242953

Nieße A, Ihle N, Balduin S, Postina M, Tröschel M, Lehnhoff S (2018) Distributed ledger technology for fully automated congestion management. Energy Inform. https://doi.org/10. 1186/s42162-018-0033-3

Palensky P, Dietrich D (2011) Demand side management: demand response, intelligent energy systems, and smart loads. IEEE Trans Ind Inform 7(3):381-388. https://doi.org/10.1109/TII. 2011.2158841

Paulus M, Borggrefe F (2011) The potential of demand-side management in energy-intensive industries for electricity markets in Germany. Appl Energy 88(2):432-441. https://doi.org/10. 1016/j.apenergy.2010.03.017

Pedram M (2012) Energy-efficient datacenters. IEEE Trans Comput Aided Des Integr Circuits Syst 31(10):1465-1484. https://doi. org/10.1109/TCAD.2012.2212898

Rausch B, Staudt P, Weinhardt C (2019) Transmission grid congestion data and directions for future research. In: Proceedings of the 10th ACM international conference on future energy systems, Phoenix, pp 443-446. https://doi.org/10.1145/ 3307772.3331018

Sáenz de Miera G, del Río GP, Vizcaíno I (2008) Analysing the impact of renewable electricity support schemes on power prices: the case of wind electricity in Spain. Energy Policy 36(9):3345-3359. https://doi.org/10.1016/j.enpol.2008.04.022

Sedlmeir J, Buhl HU, Fridgen G, Keller R (2020) The energy consumption of blockchain technology: beyond myth. Bus Inf Syst Eng 62:599-608. https://doi.org/10.1007/s12599-02000656-X

Shi Y, Xu B, Zhang B, Wang D (2016) Leveraging energy storage to optimize data center electricity cost in emerging power markets. In: e-Energy '16: proceedings of the seventh international conference on future energy systems, Waterloo, pp 1-13. https:// doi.org/10.1145/2934328.2934346
Shuja J, Madani SA, Bilal K, Hayat K, Khan SU, Sarwar S (2012) Energy-efficient data centers. Computing 94:973-994. https:// doi.org/10.1007/s00607-012-0211-2

Staudt P, Lehnhoff S, Watson R (2019) Call for papers, issue 3/2021. Bus Inf Syst Eng 61:767-769. https://doi.org/10.1007/s12599. 019-00619-X

Sze V, Chen Y-H, Emer J, Suleiman A, Zhang Z (2017) Hardware for machine learning: challenges and opportunities. In: 2017 IEEE custom integrated circuits, pp 1-8. https://doi.org/10.1109/CICC. 2017.7993626

Taylor GR (2005) Integrating quantitative and qualitative methods in research, 2nd edn. University Press of America, Lanham

Thimmel M, Fridgen G, Keller R, Roevekamp P (2019) Compensating balancing demand by spatial load migration - the case of geographically distributed data centers. Energy Policy 132:1130-1142. https://doi.org/10.1016/j.enpol.2019.06.063

Tolia N, Wang Z, Marwah M, Bash C, Ranganathan P, Zhu X (2008) Delivering energy proportionality with non energy-proportional systems: optimizing the ensemble. In: Proceedings of the 2008 conference on power aware computing and systems. San Diego

Torell W, Brown K, Avelar V (2015) The unexpected impact of raising data center temperatures. https://download.schneiderelectric.com/files?p_Doc_Ref=SPD_VAVR-9SZM5D_EN. Accessed 6 Nov 2020

United Nations (2015) Transforming our world: the 2030 agenda for sustainable development. https://sustainabledevelopment.un.org/ post2015/transformingourworld. Accessed 6 Nov 2020

Utz M, Albrecht S, Zoerner T, Strüker J (2019) Blockchain-based management of shared energy assets using a smart contract ecosystem. In: Abramowicz W, Paschke A (eds) Business information systems workshops. BIS 2018. Lecture notes in business information processing, pp 217-222. https://doi.org/10. 1007/978-3-030-04849-5_19

Vieira CCA, Bittencourt LF, Madeira ERM (2015) A scheduling strategy based on redundancy of service requests on IaaS providers. In: 23rd Euromicro international conference 2015, Turku. https://doi.org/10.1109/PDP.2015.80

Watson B, Boudreau M-C, Chen AJ (2010) Information systems and environmentally sustainable development: energy informatics and new directions for the IS community. MIS Q 34(1):23-38. https://doi.org/10.2307/20721413

Whitney J, Delforge P (2014) Data center efficiency assessment: issue paper on NRDC (The Natural Resource Defense Council)

Willms J (2019) Beyond China and North America: the decentralization of bitcoin mining. https://www.nasdaq.com/articles/ beyond-china-and-north-america\%3A-the-decentralization-ofbitcoin-mining-2019-11-04-0. Accessed 4 Nov 2020

Wu J, Tran N (2018) Application of blockchain technology in sustainable energy systems: an overview. Sustainability. https:// doi.org/10.3390/su10093067

Zhang H, Liu L, Li T (2011a) Designing IT systems according to environmental settings: a strategic analysis framework. J Strateg Inf Syst 20:80-95

Zhang Q, Zhu Q, Boutaba R (2011b) Dynamic resource allocation for spot markets in cloud computing environments. In: 2011 fourth IEEE international conference on utility and cloud computing. IEEE Computer Society, Victoria. https://doi.org/10.1109/UCC. 2011.33

Zhang Y, Wu Y, Tsang DHK, Leon-Garcia A (2018) Guest editorial special section on energy informatics for green cities. IEEE Trans Ind Inform 14:1456-1457. https://doi.org/10.1109/TII. 2018.2809575

Ziegler L, Gonzalez E, Rubert T, Smolka U, Melero JJ (2018) Lifetime extension of onshore wind turbines: a review covering Germany, Spain, Denmark, and the UK. Renew Sustain Energy Rev 82(1):1261-2127. https://doi.org/10.1016/j.rser.2017.09.100 